\title{
Analisis Penerapan Dan Pengembangan Manajemen Operasional Desain Produk Dan Rantai Pasokan Pada UKM Kelompok Pahari Palangka Raya
}

\author{
Kuwing Baboe ${ }^{1}$, Andrie Elia ${ }^{2}$, Thea Farina ${ }^{3}$, Maria Haryulin Astuti ${ }^{4}$ \\ ${ }^{1}$ Fakultas Keguruan Ilmu dan Pendidikan Universitas Palangka Raya \\ ${ }^{2}$ Fakultas Ekonomi dan Bisnis Universitas Palangka Raya \\ ${ }^{3}$ Fakultas Hukum Universitas Palangka Raya \\ ${ }^{4}$ Fakultas Pertanian Universitas Palangka Raya \\ * Correspondence author: kuing.baboe@fkip.upr.ac.id ; Tel.: +xx-xxx-xxx-xxxx
}

\begin{abstract}
This study uses a qualitative approach and the type of research used is descriptive research. Types of data are primary data and secondary data. Operational management of product design that is appropriate to increase sales results of SME Rattan Group Pahari Palangka Raya products by applying eight aspects of product design (form, features, performance, suitability, durability, reliability, style, and ease of repair) with priority on products and prices. marketed. The proper operational management of the supply chain to increase the output of the SME Rattan of the Pahari Palangka Raya Group is by implementing a multi-supplier supply chain strategy with priority on family, cost, quality and distance. The driving factor for the progress of the Pahari Palangka Raya Rattan SME Group is having a business license, emphasizing product quality and quality, affordable prices, in terms of motifs, sizes and designs that can be adjusted according to consumer desires, and timeliness of processing. While the inhibiting factors for the progress of this business are the emergence of competitors, differences in prices with other products, and the products offered have in common with other products.
\end{abstract}

\section{Keywords: Operational Management, Product Design, Supply Chain}

\begin{abstract}
Penelitian ini menggunakan pendekatan kualitatif dan jenis penelitian yang digunakan adalah penelitian deskriptif. Jenis data yaitu data primer dan data sekunder. Manajemen operasional desain produk yang tepat untuk meningkatkan hasil penjualan produk UKM Rotan Kelompok Pahari Palangka Raya yaitu dengan menerapkan delapan aspek desain produk (bentuk, fitur, kinerja, kesesuaian, ketahanan, kehandalan, gaya, dan kemudahan perbaikan) dengan prioritas pada produk dan harga yang dipasarkan. Manajemen operasional rantai pasokan yang tepat untuk meningkatkan hasil produksi UKM Rotan Kelompok Pahari Palangka Raya yaitu dengan menerapkan strategi rantai pasokan banyak pemasok dengan prioritas keluarga, biaya, kualitas dan jarak. Faktor pendorong bagi kemajuan UKM Rotan Kelompok Pahari Palangka Raya yaitu memiliki izin usaha, menekankan pada kualitas dan mutu produk, harga terjangkau, dari segi motif, ukuran dan desain dapat disesuaikan dengan keinginan konsumen, serta ketepatan waktu pengerjaan. Sedangkan faktor penghambat bagi kemajuan usaha ini yaitu timbulnya para pesaing, adanya perbedaan harga dengan produk lain, serta produk yang ditawarkan mempunyai kesamaan dengan produk lain.
\end{abstract}

Kata kunci: Manajemen Operasional, Desain Produk, Rantai Pasokan

\section{PENDAHULUAN}

Persaingan usaha pada masa sekarang semakin ketat. Pengaruh globalisasi dalam bidang teknologi informasi mengakibatkan dunia menjadi semakin terbuka, cepat, dan bersifat universal, Penyebabnya peningkatan akses informasi semakin lebih mudah. Seperti halnya dampak globalisasi dibidang teknologi yang memacu diciptanya mesin-mesin canggih yang dapat membantu pekerjaan manusia. Dampak globalisasi terbukti memberikan pengaruh besar diberbagai bidang kehidupan, termasuk bidang ekonomi. Salah satu dampak globalisasi di bidang ekonomi yang paling menonjol adalah cepatnya perubahan yang terjadi dipasar bebas, sesuai selera. Usaha Kecil dan Menengah (UKM) merupakan tulang punggung perekonomian negara. 
UKM terbukti mampu mendorong roda perekonomian bangsa untuk berputar dan mengurangi jumlah pengangguran yang ada, dengan memproduksi produk sendiri, UKM melakukan produksi hingga pemasaran secara mandiri. Di kota Palangka Raya ada 13 (tiga belas) usaha kecil dan menengah (UKM) kerajinan rotan, salah satu diantaranya yaitu UKM Rotan Kelompok Pahari Palangka Raya. Dimana rotan yang diusahakan merupakan olahan dari bahan baku setengah jadi menjadi produk jadi atau siap pakai yang memiliki nilai jual yang lebih tinggi Usaha mengolah barang siap pakai yang masih terbatas pada industri ramah tangga; home industry) seperti kerajinan rotan, tikar, tas, topi, dan lawung. Dengan melimpahnya ketersediaan bahan baku rotan di Kalimantan Tengah merupakan salah satu alasan bagi UKM Rotan Kelompok Pahari Palangka Raya menggunakan bahan baku rotan setengah jadi menjadi produk jadi. Permasalahan yang muncul dan produk hasil olahan UKM Rotan Kelompok Pahari Palangka Raya yaitu tentang desain produk yang menjadi faktor penting bagi konsumen untuk membeli suatu produk. Sangat banyak desain kerajinan rotan yang ditawarkan karena setiap konsumen memiliki selera berbeda dalam memilih desain kerajinan rotan yang ingin dibelinya. Dengan kondisi persaingan pasar yang semakin ketat, menuntut pelaku UKM Rotan Kelompok Pahari Palangka Raya untuk meningkatkan desain produk kerajinan rotan agar mampu bersaing dengan pengrajin pruduk rotan lainnya dari hasil observasi kami UKM Kelompok Pahari punya keterbatasan. Manajemen operasional erat kaitannya dengan tiga keputusan dan aktivitas utama, yaitu keputusan desain, transformasi, dan perbaikan terus-menerus atas sistem UKM Rotan Kelompok Pahari Palangka Raya belum memperhatikan tentang penerapan manajemen operasional dengan beberapa aktivitas utama. Dimana perpaduan antara desain dan transformasi untuk menciptakan nilai tambah, hal tersebut juga merupakan kendala yang dihadapi, belum sepenuhnya bisa diterapkan. Tujuan Penelitian yaitu untuk menganalisis bagaimana penerapan manajemen operasional (desain produk dan rantai pasokan) yang dijalankan oleh UKM Rotan Kelompok Pahari dan menganalisis faktor pendorong dan penghambat yang dihadapi UKM Rotan Kelompok Pahari dalam mengembangkan usaha kerajinan rotannya. Kegunaan Penelitian secara khusus adalah: Penelitian memberikan manfaat bagi semua pihak dalam pengembangan ilmu pengetahuan yang berguna untuk melanjutakan penelitian berikutnya sebagaimana penelitian ini dilakukan pada UKM Rotan Kelompok Pahari Palangka Raya, serta bahan masukan bagi instansi terkait dalam menyusun kebijakan kualitas bagi UKM dan kegunaan penelitian secara umum: sebagai bahan referensi, sumber informasi bagi masyarakat.

\section{METODE}

Penelitian ini menggunakan pendekatan kualitatif dan jenis penelitian yang digunakan adalah penelitian deskriptif. Menurut Sugiyono (2013:14), "Metode penelitian kualitatif sering disebut metode penelitian naturalistik karena penelitiannya dilakukan pada kondisi alamiah (natural setting); disebut juga sebagai metode ethnograpi, karena pada awalnya metode ini lebih banyak digunakan untuk penelitian bidang antropologi budaya; disebut sebagai metode kualitatif karena data yang terkumpul dan analisisnya bersifat kualitatif". Sugiyono (2013:56) menambahkan, "Penelitian deskriptif yaitu penelitian yang dilakukan untuk mengetahui nilai variabel mandiri, baik satu variabel atau lebih (independen) tanpa membuat perbandingan atau menghubungkan dengan variabel yang lain". Alasan menggunakan metode tersebut, karena masalah yang diteliti terjadi pada masa sekarang yaitu untuk mengetahui manajemen operasional (desain produk dan rantai pasokan) apakah yang digunakan UKM Rotan Kelompok Pahari Palangka Raya. Dalam penelitian ini yang menjadi instrumen atau alat penelitian adalah peneliti itu sendiri. Kehadiran peneliti dalam penelitian ini adalah peneliti berperan sebagai pengamat penuh, artinya peneliti hanya bertindak sebagai pengamat fenomena yang berada dalam UKM Rotan Kelompok Pahari Palangka Raya. Dalam penelitian ini peneliti sebagai pengumpul data. Jenis data yaitu data primer dan data sekunder. Data primer ini antara lain: a. Sejarah berdirinya UKM Rotan Kelompok Pahari Palangka Raya; b. Desain produk (Bentuk, fitur, kinerja, kesesuaian, ketahanan, kehandalan, gaya dan kemudahan perbaikan); c. Rantai pasokan (Hubungan pemasok dengan perusahaan, 
pengiriman, kualitas, produk, fleksibilitas dan biaya). Sedangkan data sekunder antara lain: a. Peraturan-peraturan, b. Catatan keuangan atau pembukuan, c. Semua catatan-catatan lainnya yang diperlukan. Adapun prosedur pengumpulan data yaitu dengan cara observasi berupa : Wawancara dan Dokumentasi.

\section{HASIL DAN PEMBAHASAN}

Adapun hasil penelitian dan pembahasan adalah sebagai berikut :

Hasil

1. Gambaran Umum UKM Rotan Kelompok Pahari Palangka Raya

a. Sejarah Berdirinya UKM Rotan Kelompok Pahari Palangka Raya

UKM Rotan Kelompok Pahari Palangka Raya adalah usaha perseorangan dan merupakan salah satu industri rumah tangga (home industry) di Kota Palangka Raya yang bergerak dibidang kerajinan rotan, yakni pengolahan dari bahan baku rotan setengah jadi menjadi produk jadi atau siap pakai yang didirikan pada tahun 1999 oleh Ibu Ramintje selaku pemilik usaha. Landasan hukum usaha ini didasarkan pada Surat Izin Usaha Perdagangan (SIUP) Mikro dengan Nomor: 503./225/SIUP-MIKRO/111/2011 dan telah memiliki NPWP dengan Nomor: 16.231.601.9-711.000 tertanggal 01 Juli 2011 yang beralamat di jalan RTA. Milono Km. 10 Surung I No. 48 RT. 001 RW. 001 Kecamatan Sebangau, Kelurahan Sabaru, Kereng Bankirai, Kota Palangka Raya, Provinsi Kalimantan Tengah.

Modal awal UKM Rotan Kelompok Pahari Palangka Raya pada awal berdiri tahun 1999 adalah sebesar Rp. 3.000.000,- yang digunakan sebagai pembelian bahan baku rotan setengah jadi. Seiring perkembangannya, pada tahun 2011 UKM Rotan Kelompok Pahari Palangka Raya mendaftarkan usahanya di Usaha Perdagangan Mikro (UPK) dan telah mendapat Surat Izin Usaha Perdagangan (SIUP) Mikro maka modal yang diusulkan adalah sebesar Rp. 50.000.000,-. Dimana modal yang dimaksud tidak semuanya dalam bentuk uang tunai tetapi modal yang dimaksudkan sudah termasuk peralatan dan perlengkapan seperti mesin, cat paku tembak, dan sebagainya dimana seluruh modal yang dimiliki oleh pemilik usaha dan sampai saat ini telah mengalami penambahan. UKM Rotan Kelompok Pahari Palangka Raya mendapatkan bahan baku rotan dari Barito Selatan. Selama proses produksi hingga pemasaran Ibu Ramintje dibantu oleh suami, anak, menantu dan cucu serta saudara. Dalam falsafah tumbuh dan berkembangnya suatu bisnis, perusahaan melakukan kegiatan usaha yang dimanfaatkan sebesar-besarnya agar nantinya usaha dapat berkembang dan dapat bersaing di pasar. Dalam hal ini UKM Rotan Kelompok Pahari Palangka Raya melaksanakan usahanya dengan mengolah bahan baku rotan setengah jadi menjadi produk jadi atau siap pakai seperti kerajinan rotan, tikar, tas, topi, lawung dan berbagai produk lainnya yang dapat disesuaikan dengan keinginan dan pesanan konsumen dengan wilayah pemasaran secara lokal (Kalimantan Tengah).

\section{b. Tujuan UKM Rotan Kelompok Pahari Palangka Raya}

Tujuan dari UKM Rotan Kelompok Pahari Palangka Raya adalah membangun usaha perseorang dengan memanfaatkan bahan baku rotan menjadi produk jadi atau siap pakai dan mengembangkan produk olahan rotan agar lebih bermanfaat dan bernilai ekonomis bagi masyarakat dan menjadikan produk rotan sebagai produk yang dapat bersaing di pasar nasional maupun internasional.

\section{c. Jam Kerja UKM Rotan Kelompok Pahari Palangka Raya}

Berikut adalah jam kerja UKM Rotan Kelompok Pahari Palangka Raya:

Tabel 1. Jam Kerja di UKM Rotan Kelompok Pahari Palangka Raya

\begin{tabular}{|c|c|c|}
\hline Hari & Jam (WIB) & Keterangan \\
\hline Senin-Sabtu & $08.00-12.00$ & \\
& $12.00-13.00$ & Istirahat \\
& $13.00-16.00$ & \\
\hline
\end{tabular}

Sumber: UKM Rotan Kelompok Pahari Palangka Raya Tahun 2020 


\section{d. Harga Jual Produk UKM Rotan Kelompok Pahari Palangka Raya}

UKM Rotan Kelompok Pahari Palangka Raya adalah usaha perseorangan dan merupakan industri rumah tangga (home industry) di Kota Palangka Raya yang bergerak dibidang kerajinan rotan yang kits ketahui bahwa kegiatan pokoknya yaitu mengolah bahan baku rotan setengah jadi menjadi produk jadi atau siap pakai dan kemudian dijual harga jual yang ditawarkan oleh UKM Kelompok Pahari.

Tabel 2. Harga Jual Produk UKM Rotan Kelompok Pahari Palangka Raya

\begin{tabular}{|c|c|c|c|}
\hline No. & Nama (Produk) & Harga Jual & Keterangan \\
\hline 1. & Tas Tenteng/Wanita & $\leq$ Rp. 500.000,- & 1 unit \\
\hline 2. & Tas Ransel Besar & Rp. 750.000,- & 1 unit \\
\hline 3. & Tas Ransel Kecil & Rp. 150.000,- & 1 unit \\
\hline 4. & Tas Selempang Laki-Laki & Rp. 300.000,- & 1 unit \\
\hline 5. & Tas Selempang Wanita & Rp. 350.000,- & 1 unit \\
\hline 6. & Tas Map Polos & Rp. 100.000,- & I unit \\
\hline 7. & Tas Map Motif & Rp. 150.000,- & 1 unit \\
\hline 8. & Tas Tembuleng/Gendong & Rp. 250.000,- & 1 unit \\
\hline 9. & Topi Laki-Laki/Wanita & Rp. 150.000,- & 1 unit \\
\hline 10. & Topi Pet & Rp. 100.000,- & 1 unit \\
\hline 11. & Lawung/Laki-Laki & Rp. 60.000,- & 1 unit \\
\hline 12. & Sumping/Wanita & Rp. 60.000,- & 1 unit \\
\hline 13. & Dompet Lipat & Rp. 100.000,- & 1 unit \\
\hline 14. & Dompet Klip, & Rp. 200.000,- & 1 unit \\
\hline 15. & Dompet Jenteng & Rp. 250.000,- & 1 unit \\
\hline 16. & Tikar Besar (11/2 m x 2 m) & Rp. 1.500.000,- & 1 unit \\
\hline 17. & Tikar Kecil (I m x 2m) & Rp. 1.000.000,- & 1 unit \\
\hline 18. & Tikar Panjang Batang Garing $1.000 .000,-$ & 1 unit \\
\hline 19. & Tikar Panjang Banama Tingang & Rnit \\
\hline
\end{tabular}

Sumber: UKM Rotan Kelompok Pahari Palangka Raya Tahun 2020

Tabel di atas menjelaskan harga jual produk yang ditawarkan UKM Rotan Kelompok Pahari Palangka Raya yang diketahui harga jual produk kerajinan rotan seperti tas tenteng wanita seharga $\leq$ Rp. 500.000, tas ransel besar seharga Rp. 750.000, tas ransel kecil seharga Rp. 150.000, tas selempang laki-laki seharga Rp. 300.000, tas selempang wanita Rp. 350.000 , tas map polos seharga Rp. 100.000, tas map motif seharga Rp. 150.000, tas tembuleng/gendong seharga Rp. 250.000, topi laki-laki/wanita seharga Rp.150,000, topi pet seharga Rp.100.000, lawung/laki-laki seharga Rp. 60.000 , sumping/wanita seharga Rp. 60.000, dompet lipat seharga. Rp. 100.000, dompet klip seharga Rp. 200.000, dompet jenteng seharga. Rp. 250.000, tikar besar (11/2m x $2 \mathrm{~m})$ seharga Rp. 1.500.000, tikar kecil ( $\mathrm{m} \times 2 \mathrm{~m})$ seharga Rp. 1.000.000, tikar panjang batang garing seharga. Rp. 750.000, tikar panjang banama tingang seharga Rp. 1.000.000. Adapun perbedaan harga dari 
setiap, produk yang ditawarkan oleh UKM Rotan Kelompok Pahari Palangka Raya ini disebabkan karena harga yang dipatok bukanlah merupakan harga tetap, artinya harga-harga produk tersebut dapat berubah dengan disesuaikan ukuran, tingkat kerumitan dan kesulitan, motif, dan keinginan atau pesanan konsumen.

Untuk pembelian dapat dilakukan secara langsung maupun melalui pesanan. Secara langsung artinya konsumen datang langsung ke UKM Rotan Kelompok Pahari Palangka Raya dengan memilih produk yang ada, seperti kerajinan rotan, tikar, tas, topi, dan lawung. Sedangkan pembelian melalui pesanan bisa langsung menghubungi tepon atau WhatApp (Wa) dengan jangka waktu pengerjaan tertentu yang telah disepakati oleh pengrajin dengan konsumen dan memberikan uang muka sebesar $50 \%$ dari harga produk yang digunakan sebagai pembelian bahan baku pembuatan produk yang dipesan serta sebagai jaminan atau pengikat bahwa produk tersebut akan segera diambil dan dilunasi oleh konsumen ketika produk sucfah selesai yang mans harga dan ukuran dapat disesuaikan dengan keinginan konsumen.

Berdasarkan hasil temuan dilapangan dengan melakukan wawancara terhadap pemilik UKM Rotan Kelompok Pahari Palangka Raya Ibu Ramintje pada, 11 Juli 2020. Data yang telah dikumpulkan dari hasil observasi, wawancara dan dokumentasi yang berkaitan dengan sejarah dan manajemen operasioanal desain produk dan rantai pasokan yang digunakan UKM Rotan Kelompok Pahari Palangka Raya, peneliti menyajikan hasil penelitian sebagai berikut:

a. Temuan penelitian yang ditemukan yaitu manajemen operasional desain produk di UKM Rotan Kelompok Pahari Palangka Raya dengan menerapkan delapan aspek desain produk (bentuk, fitur, kinerja, kesesuaian, ketahanan, kehandalan, gaya, dan kemudahan perbaikan) dengan prioritas pada produk dan harga .

b. Temuan penelitian yang ditemukan yaitu manajemen operasional rantai pasokan di UKM Rotan Kelomi pok Pahari Palangka Raya masih menggunakan sistim kekeluargaan dengan pemasok prioritas keluarga, biaya, kualitas dan jarak.

c. Temuan penelitian yang ditemukan yaitu faktor pendorong bagi kemajuan UKM Rotan Kelompok Pahari Palangka Raya yaitu memiliki izin usaha,sebagai kekuatan hukum untukmenjaga identitas produk sehingga kualitas dan mutu produk, harga,serta motif, ukuran dan desain dapat memenuh keinginan konsumen, serta ketepatan waktu pengerjaan. Sedangkan faktor penghambat bagi kemajuan usaha ini yaitu timbulnya para pesaing, adanya perbedaan harga dengan produk lain, serta produk juga mempunyai kesamaan dengan pruduk lain

\section{Pembahasan}

\section{Manajemen Operasional Desain Produk pada UKM Rotan Kelompok Pahari}

Berdasarkan hasil penelitian tentang manajemen operasional desain produk pada UKM Rotan Kelompok Pahari Palangka Raya, menerapkan delapan aspek desain produk untuk mencapai manajemen operasional desain produk yang tepat dan terbaik, diantaranya yaitu bentuk, fitur, kinerja, kesesuaian, ketahanan, kehandalan, gaya dan kemudahan perbaikan yang ternyata sesuai dengan teori dari salah satu pendapat ahli. Yang pertama dalam hal bentuk, dapat didiferensiasikan berdasarkan bentuk-ukuran, bentuk atau struktur fisik produk. Pada dasarnya ada bentuk kecil dan besar, perbedaan bentuk tersebut menjadi patokan yang membedakan harga masing-masing produk. Yang kedua dalam hal fitur, dapat melengkapi fungsi dasar dari setiap produk yang ditawarkan dengan penggunaan bahan baku dan kualitas rotan yang sama pada setiap jenis produk, usaha ini menggunakan kapasitas helaian rotan yang lebih banyak agar produk tetap kuat dan bertahan lama. Yang ketiga dalam hal kinerja, disini yang dimaksud adalah kualitas yang menjadi karakteristik utama produk beroperasi, UKM Rotan Kelompok Pahari Palangka Raya menjaga dan meningkatkan kualitas pada saat proses pembuatan yang dilakukan dengan benarbenar teliti agar tidak terjadi kerusakan. Ketika terdapat permintaan yang besar pemilik usaha hanya menambah jumlah persediaan atau membeli alat dan bahan lebih banyak di Yogyakarta dan Bandung. Sedangkan untuk tenaga, hanya menghubungi keluarga yang lain, meskipun beda daerah 
dan cukup memberi tahu produk apa yang diperlukan tanpa harus dipantau, karena sudah mempunyai keahlian yang sama dalam menjaga dan meningkatkan kualitas produk. Yang keempat dalam hal kesesuaian, hampir semua produk yang diproduksi sesuai dan memenuhi spesifikasi yang dijanjikan ketika sudah sampai di tangan konsumen. Namun pada saat proses pembuatan produk terjadi kecacatan, misalnya ada rotan yang putus atau sobek, maka segera menyambung atau melapisnya menggunakan lem dengan rapi agar tidak kelihatan sobek atau putusnya dan tetap terlihat sempurna. Yang kelima dalam hal ketahanan, setiap produk yang diproduksi oleh UKM Rotan Kelompok Pahari Palangka Raya dapat bertahan lama jika konsumen menjaga produk dengan baik. Pemilik UKM Rotan Kelompok Pahari Palangka Raya mengatakan bahwa produk rotan bagus terhadap sinar matahari dan tidak bagus terhadap air, tetapi ketika sudah dicat tidak bagus ditaruh dibawah sinar matahari. Yang keenam dalam hal kehandalan, suatu produk memiliki kehandalan yang dapat digunakan dalam jangka waktu yang lama. Bahan baku rotan lebih awet ketika dibuat tikar, karena jarang digunakan. Tidak seperti tas dan dompet yang hampir setiap hari digunakan, sehingga kualitas dan keawetan rotan berkurang. Yang ketujuh dalam hal gaya, produk hasil UKM Rotan Kelompok Pahari Palangka Raya memiliki beberapa motif atau gaya seperti ihing, batang garing, bejakah kelelawit dan banyak motif lainnya ada 65 motif. Penciptaan motif atau gaya termotivasi dari alam dan insting atau kreasi sendiri, bahkan bisa mengerjakan motif atau gaya berdasarkan permintaan konsumen. Untuk pewarna UKM Rotan Kelompok Pahari Palangka Raya melakukan tahap pewarnaan pada saat tahap finishing, cat kayu mengkilap yang memberikan perlindungan pada produk rotan dan tidak memiliki bau menyengat ialah cat Biovarnish. Yang kedelapan dalam hal kemudahan perbaikan, pemilik UKM Rotan kelompok Pahari Palangka Raya mengatakan bahwa usaha ini bisa memperbaiki kembali produk yang rusak, ketika produk sudah di tangan konsumen dan' mengalami kerusakan masih bisa diperbaiki, tetapi ada tambahan biaya. Karena ada konsumen yang meminta untuk dipermak lebih baik atau menambah bahan baru.

\section{Manajemen Operasional Rantai Pasokan pada UKM Rotan Kelompok Pahari Palangka Raya}

Berdasarkan hasil wawancara mengenai manajemen operasional rantai pasokan yang diterapkan UKM Rotan Kelompok Pahari Palangka Raya ialah strategi rantai pasokan banyak pemasok yang didasarkan beberapa faktor penentu strategi rantai pasokan yaitu hubungan pemasok dengan perusahaan, pengiriman, kualitas, waktu, fleksibibilitas, dan biaya. Yang pertama dalam hal hubungan pemasok dengan perusahaan, UKM Rotan Kelompok Pahari Palangka Raya mendapat pasokan bahan baku dari Barito Selatan sebanyak 4-5 pemasok dengan mempertimbangkan dari segi biaya, jarak dan kualitas tetapi lebih mengutamakan pemasok dari keluarga dengan tujuan membantu perekonomian keluarga. Yang kedua dalam hal pengiriman, pemasok selalu mengirim rotan tepat waktu ketika pemilik usaha UKM Rotan Kelompok Pahari Palangka Raya sudah mentransfer uang. Bahan baku yang dikirim secara berkala bisa dua sampai tiga kali pengiriman. Untuk mensiasati kekurangan rotan dari pemasok usaha ini menghubungi keluarga jauh-jauh hari, tapi misalkan ditempat keluarga masih kekurangan barang pasokan atau tidak mencukupi permintaan, maka keluarga langsung mencarikan pemasok yang lain untuk memenuhinya. Yang ketiga dalam hal kualitas, bahan baku dengan kualitas baik dapat mempengaruhi hasil akhir produk yang mudah dalam pengerjaan dan awet dalam pemakaian produk tersebut, pemilik UKM Rotan Kelompok Pahari Palangka Raya mengatakan bahwa dalam memilih pemasok lebih mengutamakan keluarga dan sudah tidak meragukan lagi dengan kualitas bahan baku yang dimiliki pemasok tersebut. Yang keempat dalam hal waktu, pengiriman bahan baku yang selalu datang sesuai dengan waktu yang ditentukan oleh keinginan usaha ini merupakan salah satu faktor penting dalam memilih pemasok. Pemilik UKM Rotan Kelompok Pahari Palangka Raya mengatakan bahwa bahan baku dikirim sesuai permintaan saja tidak setiap bulan dan untuk cadangan bahan baku selalu ada, karena pihak UKM Rotan Kelompok Pahari Palangka Raya selalu memproduksi setiap hari. Yang kelima dalam hal fleksibilitas disini yang dimaksud adalah kemampuan UKM Rotan Kelompok Pahari Palangka Raya untuk tetap bisa menyesuaikan secara mudah dan cepat apabila terjadi permintaan produk yang besar, yaitu dengan menghubungi 
pemasok keluarga dari Barito Selatan, tapi misalkan ditempat keluarga masih kekurangan barang pasokan atau tidak mencukupi permintaan, maka keluarga langsung mencarikan pemasok yang lain untuk memenuhinya. Yang keenam dalam hal biaya, penetapan harga bahan baku oleh pemasok tidak menjadi masalah bagi UKM Rotan Kelompok Pahari Palangka Raya tetapi lebih mengutamakan membeli dengan keluarga untuk membantu perekonomiannya Biaya pengiriman bahan baku rotan ditanggung oleh pihak UKM Rotan Kelompok Pahari Palangka Raya, dan sistem pembayaran kepada pemasok dilakukan secara Tunai melalui trasfer di bank.

Berdasarkan hasil data wawancara, UKM Rotan Kelompok Pahari Palangka Raya memiliki faktor pendorong dan faktor penghambat bagi kemajuan usahanya. Adapun faktor pendorong bagi kemajuan UKM Rotan Kelompok Pahari Palangka Raya yaitu memiliki izin usaha, menekankan pada kualitas dan mutu produk, harga terjangkau, dari segi motif, ukuran dan desain dapat disesuaikan dengan keinginan konsumen, serta ketepatan waktu pengerjaan. Sedangkan faktor penghambat bagi kemajuan usaha ini yaitu timbulnya pars pesaing, adanya perbedaan harga dengan produk lain, serta produk yang ditawarkan mempunyai kesamaan dengan produk lain.

\section{KESIMPULAN}

Simpulan sebagai berikut:

1. Manajemen operasional desain produk yang tepat untuk meningkatkan hasil penjualan produk UKM Rotan Kelompok Pahari Palangka Raya yaitu dengan menerapkan delapan aspek desain produk (bentuk, fitur, kinerja, kesesuaian, ketahanan, kehandalan, gaya, dan kemudahan perbaikan) dengan prioritas pada produk dan harga yang dipasarkan.

2. Manajemen operasional rantai pasokan yang tepat untuk meningkatkan hasil produksi UKM Rotan Kelompok Pahari Palangka Raya yaitu dengan menerapkan strategi rantai pasokan banyak pemasok dengan prioritas keluarga, biaya, kualitas dan jarak.

3. Faktor pendorong bagi kemajuan UKM Rotan Kelompok Pahari Palangka Raya yaitu memiliki izin usaha, menekankan pada kualitas dan mutu produk, harga terjangkau, dari segi motif, ukuran dan desain dapat disesuaikan dengan keinginan konsumen, serta ketepatan waktu pengerjaan. Sedangkan faktor penghambat bagi kemajuan usaha ini yaitu timbulnya para pesaing, adanya perbedaan harga dengan produk lain, serta produk yang ditawarkan mempunyai kesamaan dengan produk lain.

\section{Saran}

Berdasarkan kesimpulan tersebut, peneliti menyarankan sebagai berikut:

1. Diharapkan untuk meningkatkan prioritas terhadap produk dan harga yang dipasarkan yaitu dengan mampu memproduksi produk lebih banyak lagi tidak terikat pahari dan pada produksi keluarga saja tapi lebih dikembangkan dengan merekrut banyak pengrajin pengrajin yang baru dan berbakat dengan memberikan pelatihan bagi yang baru dengan menjalin Mitra Balai Pelatihan yang ada di maupun internasional dengan kuali8tas dan harga yang mampu bersaing serta produk UKM Rotan Kelompok Pahari Palangka Raya tetap bisa exis dipasaran

2. Diharapkan untuk pemilihan pemasok rotan tidak hanya memprioritaskan keluarga saja, tetapi - Agar pemilik usaha lebih memperbanyak pemasok dengan majalin mitra kerja pemasok lainnya baik dari dalam maupun luar Kalimantan Tengah dan terhindar dari kesulitan mencari bahan bake rotan, namun tetap mempertimbangkan dari segi biaya, kualitas, dan jarak.

3. Dilihat dari faktor penghambat bagi kemajuan usaha ini, salah satunya adalah produk yang ditawarkan sama dengan produk lain, dalam hal ini diharapkan agar pemilik usaha lebih memperbanyak kreasi dan Jenis produk serta motif lagi agar masalah ini dapat teratasi dan konsumen tetap memilih UKM Rotan Kelompok Pahari Palangka Raya untuk berbelanja kerajinan rotan.

\section{DAFTAR PUSTAKA}

\section{Adisaputo, Gunawan. 2014. Manajemen Pemasaran Analisis Untuk Perancangan}


Strategi Pemasaran. Cetakan ke-2. Yogyakarta: UPP STIM YKPN

Assauri, Sof an. 2016. Manajemen Operasi Produksi Pencapaian Sasaran Organisasi Berkesinambungan. Edisi 3, Cetakan ke-2. Jakarta: Rajawali Pers.

Dudung, Agus. 2012. Merancang Produk. Bandung: PT Remaja Rosdakarya.

Haizer, Jay dan Render, Barry. 2016. Manajemen Operasi: Manajemen Keberlangsungan dan Rantai Pasokan. Edisi ke-11. Jakarta: Salemba Empat.

Haming, Murdifin dan Nurnajamuddin, MAW. 2011. Manajemen Produksi Modern Operasi Manufaktur dan Jaw. Edisi ke-2. Buku 1. Jakarta: PT Bumi Aksara.

Jacobs, Robert F dan Chase Richard B. 2015. Manajemen Operasi dan Rantai Pasokan. Edisi ke-14. Buku 1. Jakarta: Salemba Empat.

Kotler, Philip. 2008. Manajemen Pemasaran. Jakarta: Erlangga.

Kotler, Philip dan Keller, Kevin L. 2009. Manajemen Pemasaran. Edisi ke-13. Jilid 1 dan 2. Jakarta: Erlangga.

Ma'arif, M. Syamsul dan Tanjong, Hendri. 2003. Manajemen Operasi. Jakarta: PT Grasindo.

Moleong, Lexy J. 1990. Metodologi Penelitian Kualitatif Bandung: PT Remaja Rosdakarya.

Sugiyono. 2013. Metode Penelitian Pendidikan Pendekatan Kuantitatif, Kualitatif, dan R\&D. Bandung: Alfabeta.

Sugiyono. 2015. Metode Penelitian Pendidikan Pendekatan Kuantitatif, Kualitatif, dan R\&D. Bandung: Alfabeta

Tjiptono, Fandy. 2008. Strategi Pemasaran. Yogyakarta: ANDI.

\section{Sumber Internet:}

Alfianto, Eko Agus. 2014. Pengaruh Desain Produk Dan Layanan Purna Jual Terhadap Keputusan Konsumen Membeli Sepeda Motor Yamaha Merek New V-Ixion F1 (Full Injection). Diunduh pada tanggal 9 Januari 2019, dari https://doeplayer.info/221755-Pengaruh-desain-produkdan-layanan-purna-jual-terhadap-keputusan-konsumen-membeli-sepeda-motor-yamahamerek-new-v-ixion-fi.html

Riskiya, Eka. 2012. Analisis Strategi Desain Produk Dalam Meningkatkan Volume Penjualan Pada Produk Mebel Antik CV. Gardu Antique Indah Situbondo. Diunduh pada tanggal 9 Januari 2019, dari http://etheses.uinmalang. ac. id/2023/2/08510141_Indonesia.pdf.

Renata, Rio Pascal. 2018. Implementasi Supply Chain Management (SCM) Pada UKM Emping Mlinjo Di Sukoharjo. Diunduh pada tanggal 9 Januari 2019, dari http://eprints.ums.ac.id/60958/12/NASKAH\%20PUBLIKASI_Riojibraiy ums.pdf

Oktaviani, Olivia. 2015. Pengaruh Desain Produk Terhadap Keputusan Pembelian Konsumen (Studi Kasus Pada Distro Flashy Bandung). Diunduh pada tanggal 20 Desember 2018, dari http://repository.unisba. ac.id/handle/ 123456789/128

Wicaksono, Satria Adhi. 2015. Pengaruh Merek dan Desain Terhadap Minat Beli Konsumen. Diunduh pada tanggal 20 Desember 2018, dari http: lib. unnes. ac. id/2/460 https://www.google.comlurl?sa--t\&source--web\&rct--j\&url= https: Ilwww.bi.go.IcLli d/tentang-bi/uu- bi/Documents/ UU20 Tahun 2008UMKM. pdf\&ved=2ahUKEvjSgNiV5oPg AhVLQ18KI4WKxCd4QFjAAeg QIBRAB \& usg=AOvVawl9LC8HiAxurh WX8bbD7nTR- Di unduh pada tanggal 20 Desember 2018

https://www.google.com/url?sa--I\&source--web\&rct--j\&url=http://eprints.umpo.ac .id/4123/3/3.0/o2520BABO/o252011.pdf\&ved=2ahUKEwjjsJWokf

fAhWwg UsFHVV-DfEQFjAAegQIAhAB\&usg=AOvVaw3EOeinimubDmvoZliQK67yZ\&csh id=1548082798926. Di unduh pada tanggal 15 Januari 2019

https://www.google.comlurl?sa--I\&source--web\&rct--j\&url=http:IIrepository.unpa ac.id/28824/6/10.\%2520BAB\%252011.pdf\&ved=2ahUKEwIC4NIrmmf fAhVli3AKHb2tBuAQFjABegQIAhAB\&usg=AOvVawOk8egaEOY91VOPEdhOrxW. Di unduh pada tanggal 20 Desember 2018 
https://www.google.comlurl?sa--t\&source--web\&rct--j\&url=https:Ilrepository.wid yatama.ac.id/xmlui/bitstream/handle/l 23456789/362 I/Bab`25202.pdf\%3 Fsequencel/o3D7\&ved=2ahUKEwjyz6yY.m-fAhWMto8KHTZrb68QFj AAegQIBRAB\&usg=AOvVaw3PInAB2cYbW6j 50wJ5jAFL Di unduh pada tanggal 20 Desember 2018

https://www.google.com/url?sa--t\&source--web\&rct--j\&url=https://Yosnex.files.w ordpress.com/2016/09/11 - sluipsi-scm-rantai- pasok. pdf\&ved= 2ahUKEwiY 91baovfAhUQal8KHW4N4B2IQFjAAegQI AxAB\&usg=AOvVawl xn Gbuiz OYAFt2ZxdCGdSi. Di unduh pada tanggal 27 Desember 2018 